http://dx.doi.org/10.30681/23588403v13i01150170

\title{
A DROGA DA OBEDIÊNCIA: UMA PROPOSTA DE MULTILETRAMENTO LITERÁRIO POR APLICATIVO MÓVEL
}

Data de recebimento: $14 / 12 / 2018$

Aceite: 18/03/2019

\author{
Nilza Pereira CREPALDI (UEM/PROFLETRAS) ${ }^{1}$ \\ Patrícia Santos de SOUZA (UEM/PROFLETRAS) ${ }^{2}$ \\ Rosângela Fernandes de OLIVEIRA (UEM/PROFLETRAS) ${ }^{3}$
}

\begin{abstract}
Resumo: As tecnologias digitais trazem uma nova forma de ler/escrever e, com isso, surgem novos suportes de leitura e uma nova configuração de autor/leitor. Diante disso, o artigo apresenta uma forma diferente de ensinar leitura na escola por meio de um protótipo didático, disponibilizado em aplicativo móvel, com base nas concepções de linguagem sociointeracionistas (BAKHTIN, 1992; 2003) e nas metodologias de leitura de Cosson (2014) e nas de multiletramentos de Rojo (2012). O aplicativo é endereçado a professores do Ensino Fundamental II, com uma prática de ensino de leitura literária direcionada a alunos do nono ano e mediada pela obra "A droga da obediência" de Pedro Bandeira em diálogo com outros gêneros de diferentes esferas de circulação.
\end{abstract}

Palavras-chave: Leitura. Ensino. Multiletramentos. Protótipo Didático.

Abstract: Digital technologies bring a new way of reading / writing and, with this, new reading media and a new author / reader configuration appear. The article presents a different way of teaching reading in the school through a didactic prototype, made available in a mobile application, based on the conceptions of socio-interactionist language (BAKHTIN, 1992, 2003) and Cosson's reading methodologies (2014) and Red's multiletramentos (2012). The application is addressed to Primary School Teachers II, with a literary reading teaching practice aimed at ninth grade students and mediated by the work "The drug of obedience" of Pedro Bandeira in dialogue with other genres of different spheres of circulation.

Keywords: Reading. Teaching. Multiletramentos. Didactic prototype.

\section{Introdução}

O artigo aqui apresentado é resultado de estudos desenvolvidos durante o curso Mestrado Profissionalizante de Letras (Profletras/UEM/2017-2018) e parte da seguinte questão: como suscitar no aluno do nono ano do Ensino Fundamental II o entusiasmo e empenho pela

\footnotetext{
${ }^{1}$ Professora da rede pública de ensino fundamental II e ensino médio de Marialva/Pr/Brasil, graduada em Letras (1983), pós-graduada em Literatura brasileira (1995), Administração Pública (1998), EAD e as Tecnologias Educacionais (2015), mestre em Letras (2018/PROFLETRAS/UEM/PR).

${ }^{2}$ Professora da rede pública de Ensino Fundamental I, II e Ensino Médio de Flórida/Pr/Brasil, graduada em Letras (2006) e em Pedagogia (2017), pós-graduada em Educação Especial (2007), discente no Mestrado Profissional em Letras - PROFLETRAS (UEM/PR).

${ }^{3}$ Professora da rede pública de ensino - fundamental II e Ensino Médio de Campo Mourão/Pr/Brasil, graduada em Letras, pós-graduada em Literatura Brasileira, Linguística aplicada ao ensino de Língua Portuguesa, Psicopedagogia Clínica e Institucional; discente no Mestrado Profissional - PROFLETRAS (UEM/PR).
} 
leitura de modo que ele desenvolva o seu letramento literário e a sua humanização? E para tentar responder à problematização, desenvolvemos um protótipo didático de leitura, com base nas concepções teóricas de Bakhtin e seu Círculo de estudos (1992; 2003), nas metodologias de Cosson (2014) e nos estudos de Rojo (2012; 2013) sobre multiletramentos, disponibilizado em um aplicativo móvel (app) educacional ${ }^{4}$, como uma estratégia pedagógica organizadora para aulas de Língua Portuguesa.

O software é endereçado a professores do Ensino Fundamental II, com sugestões de atividades para alunos do $9^{\circ}$ ano sobre a leitura da obra "A droga da obediência”, de Pedro Bandeira, estendendo diálogo com outros gêneros discursivos e suas múltiplas vozes: ilustrações, vídeos, áudios, jogos, noticiário, filme, resumo, tira, entre outros. Estrutura-se em uma concepção de linguagem como prática social, embasada nos estudos de Bakhtin (2003) e de seu Círculo.

A produção didática por meio de um aplicativo móvel justifica-se pelo fato de que a Base Nacional Comum Curricular (BNCC) defende que o texto em sua modalidade verbal articulada com o visual, o sonoro, o digital, entre outras, seja o centro para as práticas de linguagem. $\mathrm{O}$ documento alega que o uso das novas tecnologias enriquece o ensino sistematizado na escola de modo que o aprendiz se constitui um coautor proativo do conhecimento. Mas, ressalta que as escolas devem oferecer suporte pedagógico para que um trabalho como esse se efetive na prática (BRASIL, 2017).

A partir das teorias dos multiletramentos do Grupo de Nova Londres (GNL), com a pós-globalização e a inserção das Tecnologias Digitais da Informação e Comunicação (TDICs), Rojo (2012) acredita que novas formas de ler e escrever associadas a novas maneiras de ver e compreender o mundo devem ser inseridas nas escolas em todos os níveis, incluindo o ensino fundamental, pois os alunos precisam lidar com as linguagens de sua prática social. Nesse novo contexto de cultura híbrida, a autora assinala que a escola deve estar comprometida com um processo de ensino e aprendizagem da leitura por meio da cibercultura, mesmo porque sem isso não há como participar de forma ética, crítica e reflexiva da sociedade à qual está inserido. Para a escritora, as práticas de leitura, sejam elas literárias ou não, devem considerar o hibridismo da linguagem e as multissemioses, pois as culturas estão se inter-relacionando. Por isso, há a necessidade de que a escola trabalhe com a diversidade de gêneros e suportes apresentados também pelas novas tecnologias digitais.

\footnotetext{
${ }^{4}$ Disponível em: https://app.vc/adrogadaobediencia. Acesso em: 17 jul. 2018.
} 
Por isso, Rojo sugere os protótipos didáticos como uma opção metodológica que propicia ao professor na escola criar, adaptar, complementar, acrescentar, refutar, aceitar, etc. Essa metodologia desconstrói os modelos tradicionais de planos de ensino prontos e acabados, copiados pelos professores dos livros didáticos, visto que, com essa prática, o professor transforma-se em produtor do conhecimento. Para a autora, "Os protótipos didáticos são estruturas flexíveis e vazadas que permitem modificações por parte daqueles que queiram utilizá-las em outros contextos que não o das propostas iniciais" (ROJO, 2012, p. 8).

O protótipo trata-se de um método pedagógico de natureza multimodal que prevê o uso de redes sociais, hyperlinks, plataformas digitais, aplicativos, etc., exigindo novas capacidades e habilidades de compreensão e de recepção, tanto do aluno, quanto do professor, com o propósito de inseri-los na prática dos multiletramentos. Tal prática metodológica requer uma ressignificação dos papéis tanto do professor quanto do aluno, e propicia ao professor fazer adaptações ao acervo relacionando-as ao tema principal da proposta, possibilitando-lhe acompanhar o trabalho interativo dos alunos (ROJO, 2012).

Diante disso, pretendemos aqui apresentar um aplicativo como alternativa de explorar a leitura literária, de modo que novas formas de ler sejam inseridas na escola de ensino fundamental II, substituídas por práticas mais interativas e proativas e menos centradas na figura do professor. Ademais, disponibilizamos um novo instrumento de trabalho com a leitura literária, instituindo ao professor a condição de produtor do seu próprio material didático e ampliando as suas expectativas de pesquisa. Além do mais, o contexto de hoje, dominado pelas práticas sociais digitais, vem exigindo cada vez mais de nós professores novas formas de contextualizar o processo de ensino e aprendizagem da leitura, a fim de dinamizarmos o processo de desenvolvimento do multiletramento literário do nosso aluno do ensino fundamental II.

Dessa forma, com o intuito de aguçarmos o interesse dos estudantes em termos de engajamento pela leitura e apreciação pela criação artístico-literária, formação pessoal, cultural e social, elaboramos este protótipo didático com diversas atividades de ensino para a leitura disponibilizado em app. A escolha da obra de Pedro Bandeira justifica-se por ter um enredo que prende a atenção do leitor adolescente, despertando a sua curiosidade pelo jogo de imaginação que é explorado durante a narrativa. Além disso, apresenta personagens com idades próximas às dos estudantes desta fase, possibilitando-lhes a coautoria da obra e a associação da história à sua realidade. A intenção é proporcionarmos uma prática educativa que ajude o 
aprendiz a conhecer a obra literária de mistérios/enigmas, bem como, compreendê-la e interpretá-la, visando ao seu multiletramento literário e, sobretudo, à sua formação humana.

\section{Da teoria à prática}

\subsection{A leitura como prática social}

Trabalhar a leitura como uma prática social na escola é considerar as concepções de linguagem bakhtiniana. Bakhtin (2003) e o seu Círculo de estudos propõem uma concepção enunciativa e dialógica da linguagem, que parte do pressuposto de que todos os campos da atividade humana estão ligados ao uso da língua (gem) e que, é na interlocução e na interação que ela se efetiva como prática social, por meio de enunciados (orais e escritos) concretos e únicos; descritos pelos estudiosos como a real unidade da comunicação discursiva, sendo, portanto, heterogêneos oriundos da multidão de vozes que possibilitam a constituição do sujeito discursivo. Bakhtin denomina esses enunciados como gêneros do discurso, que, segundo ele, são "tipos relativamente estáveis de enunciados" (BAKHTIN, 2003, p. 262), isto é, são formas de textos criados pelos sujeitos na sociedade, que funcionam como mediadores entre o autor e o destinatário.

Para o filósofo da linguagem, a noção de gênero comporta uma arquitetônica que inclui conteúdo temático, unidade temática, forma composicional, estilo, entonação expressiva, autor, destinatário e aponta para uma dimensão extra verbal ao incluir os modos de produção e circulação, os fatores sócio-históricos, assim como os valores constituídos socialmente, que se fundem no todo do enunciado e são marcados pela especificidade de cada esfera da comunicação. A variedade da atividade humana não se esgota e, consequentemente, a riqueza e a diversidade de gêneros são infinitas, cuja distinção e classificação em gêneros primários (simples) e secundários (complexos) decorrem do uso da linguagem em diferentes situações/contexto e condições de produção do enunciado (BAKHTIN, 2003).

Ressaltamos assim a importância de lidar, na escola, com os textos como gêneros, ou seja, como situações de produção dos enunciados em seus aspectos sociais e históricos, levando em conta os contextos e as relações sociais reais dos agentes, bem como as ideologias que emergem dos discursos. Por esse motivo, além de tratar a leitura apresentando a sua finalidade, o seu endereçamento, o mediador precisa discutir com o aluno: (a) as condições de produção da obra/texto; (b) a situação social imediata e o contexto social mais amplo de leitura; (c) verificar sobre o que o texto fala, isto é, o tema; (d) quais os recursos empregados para mostrar 
o conteúdo temático, ou seja, conhecer como o texto se estrutura formalmente; (e) identificar o estilo individual do sujeito-autor; (f) compreender as relações interdiscursivas, intradiscursivas e intertextuais que envolvam a leitura e que possibilitam ao aluno/leitor compreender os "jáditos" e o que ainda poderá "ser dito" sobre o texto.

Assim, ao compreender e interpretar o sentido linguístico da obra/texto, o aluno terá condições de responder concordando ou discordando, complementando, aplicando o discurso ou preparando-se para empregá-lo e, com isso, poderá dar uma resposta oral, escrita, visual, sonora, digital, etc., manifestando a sua individualidade e com condições de assumir a coautoria do que está lendo, compreendendo a vida e se preparando para lidar com ela.

\subsection{As tecnologias digitais e o ensino da literatura}

No contexto atual, as pessoas se relacionam com novas formas de viver e, com um clique, conseguem, pela internet, se conectar e interagir com as mais diferentes linguagens e culturas. A escola, por sua vez, não pode ignorar as potencialidades oferecidas pela cibercultura, sendo que os recursos que ela oferece, tanto ao produtor quanto ao leitor, tornam-se fundamentais para aguçar a interatividade e dinamicidade durante o processo de produção da leitura.

Em relação ao uso das tecnologias em sala de aula, Rojo (2012) afirma que os educadores precisam estar familiarizados com a "revolução da informação" para saberem o momento de intervir positivamente e usar estratégias críticas voltadas ao ensino do multiletramento, bem como, fazer uso adequado dos diversos recursos de multimídias dos quais dispõem. Nesse sentido, para implementar o trabalho aqui descrito, além de outros recursos, propõem-se aqui o protótipo didático, cujo conceito circula desde os meados de 2011, como material didático virtual de apoio que combina o impresso e novas modalidades de linguagens.

Rojo (2017) explica que apesar de ser parecidos com as sequências didáticas, os protótipos se diferenciam destas por ter uma estrutura flexível, possibilitando ao professor acrescentar ou excluir para atender à realidade de seus alunos, confirmando o papel de autoria do mediador durante o processo. Acerca dessa conceituação, Rojo (2012) explica que se costuma associar protótipo a modelo, ou seja, seria uma ideia primeira e que pode ser copiado ou imitado. 
Entretanto, "os protótipos de ensino podem ser definidos como "esqueletos" a serem preenchidos levando-se em conta as particularidades do contexto de ensino" (MARSAROPAVAN, 2017, p. 105). Marsaro-Pavan aponta que "no formato de livros digitais interativos, os protótipos permitiriam "interatividade com o material, navegação, multissemiose e hipermídia, de maneira muito fácil” (MARSARO-PAVAN, 2017, p. 108).

Rojo (2017) confirma essa proposição salientando que,

“[...] protótipo, em resumo, é um material navegável e interativo [...] mas com um discurso autoral/professoral que conduza os alunos a um trabalho digital aberto, investigativo e colaborativo, mediado pelo professor, e que abra a esse professor possibilidades de escolha de acervos alternativos ao acervo principal da proposta didática, de maneira a poder acompanhar o trabalho colaborativo dos alunos" (ROJO, 2017, p. 18).

Marsaro-Pavan (2017, p. 105) menciona algumas características dos protótipos de ensino apontadas por Rojo. São elas: (a) grande capacidade de armazenamento e acessibilidade democrática, já que estão alocados nas nuvens; (b) utilização de ferramentas colaborativas públicas e gratuitas como o Prezi e o Google Docs, permitindo a interação colaborativa entre professores e alunos; (c) uso de ferramentas combinadas a banco de dados, facilitando a preparação das aulas pelo professor e garantindo a flexibilidade e a adaptabilidade dos materiais; (d) presença de princípios de ensino e de aprendizagem robustos; a estrutura hipertextual, hipermidiática e multimodal, que coloca semioses e mídias em diálogo; (e) o caráter multicultural que, emprestando o conceito de Garcia-Canclini (2008[1989]), sempre combina diferentes coleções culturais.

Para Rojo (2017), o protótipo didático possibilita à escola incorporar atividades digitais às atividades impressas, proporcionando aos alunos o conhecimento de diferentes gêneros, suportes e mídias, por meio de atividades pedagógicas que possibilitem acesso a novos espaços de circulação. Permite, também, que o professor traga diferentes propostas metodológicas dependendo dos objetivos curriculares a atingir. Enfim, como se pode observar, o protótipo didático ou protótipo de ensino, possibilita uma forma instigante de propiciar o ensino interativo ao estudante, constituindo-o como sujeito de seu dizer e fazer, outorgando ao professor a função de produtor e mediador no processo de ensino e aprendizagem.

Contudo, como asseveram Da Silva \& Souza (2015), essa nova estratégia de ensino o protótipo - não depende apenas do professor, porque demanda e exige tempo e condições 
favoráveis ao estudo, elaboração e aplicação. Portanto, a difusão dessa metodologia pedagógica como forma de democratizar o acesso ao conhecimento por meio dos recursos tecnológicos contemporâneos é, também, e principalmente, uma questão de políticas públicas.

\subsection{Saber e prazer: o ensino da leitura literária na escola}

Como este trabalho enfoca o estudo da narrativa de enigma policial, é indispensável refletir que: "A literatura é, pois, um sistema vivo de obras, agindo umas sobre as outras e sobre os leitores; e só vive na medida em que estes a vivem, decifrando-a, aceitando-a, deformandoa" (CANDIDO, 2000, p. 68). Nesse sentido, há uma interinfluência entre autor, obra e leitores que se encontram em sociedade e convivem em uma relação dialética.

Segundo Candido (2002) a literatura possui três funções: psicológica, formativa e de conhecimento do mundo e do ser. Diante disso, ela tem o poder de libertar da alienação e da opressão, como também esclarece Compagnon (2009, p. 34) dizendo que "a literatura, instrumento de justiça e de tolerância, e a leitura, experiência de autonomia, contribuem para a liberdade do indivíduo". Consoante Candido, sendo um direito, o equilíbrio social depende dela, porque "A literatura confirma e nega, propõe e denuncia, apoia e combate, fornecendo a possibilidade de vivermos dialeticamente os problemas" (CANDIDO, 1995, p. 175).

Além disso, Candido (1995, p.191) enfatiza que "uma sociedade justa pressupõe o respeito aos direitos humanos, e a fruição da arte e da literatura em todas as modalidades e em todos os níveis é um direito inalienável”. Diante disso, compete à escola pública prover o acesso à literatura, uma vez que ela atende as camadas mais desprivilegiadas desse bem e, negála, é negar um Direito humano. O fato de ser ensinada na escola para garantir a função essencial de construir e reconstruir a palavra que humaniza requer um trabalho didático-pedagógico organizado e sistematizado para que se propicie e amplie o letramento literário, compreendido como uma prática social de responsabilidade da escola (COSSON, 2014).

Apesar da pesquisa abranger o estudo de outros gêneros do discurso (filme, vídeo, tira, etc.) e também aspectos quanto à navegação online, o enfoque é dado para a leitura literária cognitiva que só se torna relevante e sistematizada pelo respaldo de metodologias que considerem o prazer e o saber que o texto oferece, de modo que o leitor compartilhe com o outro os seus conhecimentos prévios e as suas impressões por meio da análise das condições de produção e de recepção da leitura. Além do que, o fato de lidar com o texto literário como 
gênero faz com que esta pesquisa não fique apenas nos estudos dos elementos da narrativa de suspense/policial.

Diante disso, para harmonizar os conceitos já discutidos, relacionando-os a uma prática social de leitura literária em sala de aula, apresentamos as concepções de Cosson (2014), a fim de orientar didaticamente a materialização dessa teoria. Este autor acredita que a literatura deve ser ensinada na escola para garantir a função essencial de construir e reconstruir a palavra que torna o homem mais humano. Isso tudo pressupõe um trabalho didático-pedagógico organizado por parte do professor de Língua Portuguesa para possibilitar e ampliar o letramento literário, porque é uma forma de assegurar o seu efetivo domínio.

Por isso, é essencial escolarizar a literatura, criando na escola uma comunidade de leitores que possa se expandir para fora dos seus muros, fornecendo ao aluno/leitor uma maneira própria de ver e lidar com o mundo. Praticar literatura pela leitura ou pela escrita é explorar a linguagem de forma que as regras impostas pelos discursos padronizados sejam desconstruídas (COSSON, 2014).

A análise literária na escola, conforme Cosson (2014), exige do aluno/leitor respostas, levando-o a descobrir os segredos da construção do texto literário, interagindo mais com a obra/texto lido. Por isso, a literatura não é apenas a reelaboração de um conhecimento, mas a incorporação do outro pelo leitor sem que ele perca a sua individualidade. E o leitor não só aprende a vida pela experiência do outro como faz com que ele também vivencie essa experiência.

Nesta perspectiva é atribuição da escola trabalhar a literatura na escola para que o aluno atinja as habilidades previstas pelas expectativas de aprendizagem. Nesse sentido, a leitura literária deve ser prazerosa, mas só terá esse efeito se o aluno descobrir os segredos que se escondem nela pelo tratamento de sua linguagem por meio da discussão coletiva, analisando o conteúdo temático, a sua estrutura, a magia e ideologia reveladas via suas relações dialógicas, o trabalho linguístico e semiótico que determina a individualidade do autor, as condições histórico-sociais em que foi produzida, quem são os seus potenciais leitores e em que contexto está sendo recebida.

O professor de português deve incentivar os alunos/leitores à leitura literária porque estes devem aprender a refletir, a se identificar com as personagens, a vivenciar situações conflituosas e aguçar a sua sensibilidade e a criticidade, de modo que encontrem respostas para as suas dúvidas e se preparem para a vida em sociedade. Além do que, em um contexto movido pelas tecnologias digitais, é preciso repensar o papel do aluno como leitor e produtor de textos, 
possibilitando-lhe condições para que as funções de leitor/autor e de produtor interativo também sejam exercitadas na escola com diferentes metodologias e que envolvam diferentes linguagens.

Na acepção de Cosson (2014), a leitura de um texto ou obra literária deve envolver saber e prazer, por isso, o processo poderá abranger os seguintes aspectos: motivação, introdução, leitura e interpretação, pela sequência normal; e motivação, introdução, leitura, contextualização, expansão e interpretação da leitura, pelo uso da sequência expandida.

Abaixo, segue um quadro (Quadro 1) representativo da sequência expandida de Cosson.

Quadro 1 - Sequência didática expandida (COSSON, 2014)

\begin{tabular}{|c|c|c|}
\hline \multicolumn{3}{|c|}{ SEQUÊNCIA DIDÁTICA EXPANDIDA } \\
\hline Fase 1 & Motivação & $\begin{array}{l}\text { Mobilização dos alunos para a leitura pelo professor, motivando-os e } \\
\text { problematizando o tema. }\end{array}$ \\
\hline Fase 2 & Introdução & $\begin{array}{l}\text { Apresentação da obra/texto ao aluno, aproximando-o da leitura pelo } \\
\text { reconhecimento do livro (suporte), condições de produção/recepção, } \\
\text { suporte (capa, contracapa, etc.) discussão da vida do autor, análise dos } \\
\text { indícios e fase hipotética pelas ilustrações e título. }\end{array}$ \\
\hline Fase 3 & Leitura & $\begin{array}{l}\text { Leitura silenciosa/individual e oral/coletiva da obra/texto. Professor } \\
\text { convida alunos a apresentarem os resultados de sua leitura por meio de } \\
\text { questões (orais e escritas) mais específicas sobre o andamento da } \\
\text { história lida em pequenos intervalos. Durante esses intervalos de } \\
\text { discussão, o mediador ficará sabendo sobre as dificuldades dos alunos } \\
\text { em relação à leitura, estimula-os, sana suas dúvidas inclusive a de } \\
\text { vocabulário. Essa etapa é a fase do } \\
\text { compartilhamento/discussão/interação e da construção de sentidos da } \\
\text { leitura. }\end{array}$ \\
\hline Fase 4 & Contextualização & $\begin{array}{l}\text { Apresentação de atividades, durante a leitura (fase } 3 \text { ), que levem o } \\
\text { aluno a relacionar o texto à sua realidade, refletindo o seu contexto de } \\
\text { forma crítica e autônoma. }\end{array}$ \\
\hline Fase 5 & Expansão & $\begin{array}{l}\text { Proposição de atividades que ultrapassam as expectativas da primeira } \\
\text { leitura, podendo ser uma leitura complementar, um filme, uma } \\
\text { pesquisa, um documentário, etc. ligados ao tema discutido na primeira } \\
\text { leitura ou outra atividade que possa ampliar a visão de mundo do } \\
\text { aprendiz por meio das relações intertextuais e associações de ideias. }\end{array}$ \\
\hline Fase 6 & Primeira Interpretação & $\begin{array}{l}\text { Etapa em que o leitor constrói sentidos particulares sobre o que leu. O } \\
\text { leitor reflete o que lê de forma implícita e explícita. Leitor dialoga com } \\
\text { os demais leitores sobre o sentido da leitura para a sua vida, ampliando } \\
\text { os horizontes de expectativas no coletivo. }\end{array}$ \\
\hline Fase 7 & Segunda interpretação & $\begin{array}{l}\text { Registro (produção oral, escrita, visual, em áudio, midiática, plástica, } \\
\text { etc.) do leitor sobre a obra, por diferentes recursos estabelecendo um } \\
\text { diálogo entre leitor e comunidade escolar. }\end{array}$ \\
\hline
\end{tabular}

Fonte: As autoras. 
Convictos de que a sequência didática expandida se adequava melhor aos propósitos deste trabalho, optamos pelo uso desta sequência para a elaboração do protótipo, procurando assegurar ao aluno: (a) apresentar o que já conhece sobre a leitura; (b) inferir e realizar hipóteses; (c) manter relações entre um texto e outro; (d) analisar os elementos que constituem o texto e dar maior sentido para ele; (e) interagir com o outro, pesquisando, jogando e argumentando; (f) ampliar seu universo literário; (g) contextualizar as situações apresentadas; (h) responder ao processo.

\subsection{A obra}

A Droga da Obediência é uma narrativa em prosa escrita por Bandeira (2014), da coleção Os Karas, destinada ao público adolescente, estruturada em 30 capítulos. Em 1984 foi publicada a sua primeira edição pela Editora Moderna, mas teve novas edições em 1992, 1995, 2003, 2009 e 2014. A história tem como cenário principal uma escola particular de São Paulo, alunos, professores e diretor. Miguel é aluno e líder de um grupo chamado "Karas" que desvenda crimes e mistérios. Além dele, o grupo é composto por Crânio, o mais esperto, Magri, a melhor atleta da escola, Calu, o melhor ator e Chumbinho, o último a aderir ao grupo.

O enigma inicial é o desaparecimento de jovens estudantes de colégios particulares paulistas, o que incita os meninos a investigar o mistério. Detetives por acaso, os Karas, aos poucos, vão solucionando os mistérios, ajudados por Chumbinho que adere ao grupo por pressão e se deixa raptar para descobrir os segredos dos criminosos. Com a interferência de Chumbinho e deduções lógicas, os jovens detetives percebem que a droga chega às escolas por meio de um traficante, Bino, que se matricula e depois desaparece com mais dois estudantes. Os jovens capturados são conduzidos à indústria "Pain Control", onde fícam presos sob o domínio da droga fazendo tudo o que a organização determina. O objetivo dos bandidos é transformar os jovens em seres perfeitos, "robotizados" e capazes de superar o medo, dotandoos de poderes físicos, porém, sem nenhuma capacidade criativa. Depois de muitas aventuras, os Karas descobrem o esconderijo dos criminosos e revelam a identidade do líder, o Dr. Q.I., que se disfarçava de diretor liberal-democrata do Elite, colégio onde estudam.

Trata-se de uma história que atrai o jovem leitor com alguns elementos que a aproximam de um romance policial "noir", tais como: (a) crimes: raptos de garotos, assassinato de Bronca, etc.; (b) detetives: os Karas, jovens que desvendam os crimes, e o policial adulto Andrade; (c) 
força mítica dos heróis (os Karas) que, por meio de façanhas, procuram realizar transformações no contexto em que vivem, retomando modelos do passado, onde herói e vilão estão presentes; (d) criminosos: Dr. Q. I., líder criminoso; Coisa, Animal e Fera, seguranças dos bandidos; Bino, traficante disfarçado de estudante; Rubens, policial aliado aos criminosos; (e) personagens bem humanizadas e caracterizadas por meio de suas ações, dos espaços e tempo onde são colocadas, enraizando a ficção no real; (f) personagens que trabalham em recintos abertos, em ação corporal contra os suspeitos, correm risco de vida enfrentando perigos constantes; (g) linguagem simples, direta, cheia de suspense, norteada pela gradação de efeitos da aventura e do mistério; (h) a divisão dos títulos de capítulos enfatiza a trama, tem poder de mistério e aguça a curiosidade do leitor, constituindo-se ganchos para o desenrolar dos acontecimentos; (i) o romance começa pelas causas para se chegar aos efeitos e há uma gradação dos efeitos de aventura e mistério na obra com pistas que vão se acumulando, algumas reveladas pelo grupo e outras, pelo próprio leitor; (j) a participação do leitor na tarefa de deduzir o caráter e os sentimentos das personagens por meio de suas ações. Impulsionado pelos enigmas, o leitor se vê como parceiro dos jovens detetives; $(\mathrm{k})$ o criminoso não é somente revelado, mas agarrado fisicamente e pelo seu comportamento autoritário; (l) presença do triângulo amoroso: romance entre Miguel com Magri e o interesse de Crânio por Magri.

Todas estas características permitem a interação do leitor na trama, explorando sua curiosidade pelos crimes e pelo jogo de imaginação. Esse magnetismo, que atrai e aguça o desejo pela leitura, é o que justifica a escolha do livro para ser trabalhado com alunos do $9^{\circ}$ ano do ensino fundamental.

\subsection{O protótipo didático em aplicativo móvel}

A BNCC (2017) trouxe mudanças a respeito de objetos de conhecimento e novas habilidades que o aluno deve adquirir no ensino fundamental II, dentre elas destaca-se a necessidade do professor, durante o trabalho de leitura e produção textual, inserir em sala de aula estratégias que envolvam o uso dos mais diferentes suportes, destacando-se os digitais. Exatamente por isso o documento traz as práticas culturais das tecnologias de informação e comunicação para serem trabalhadas na sala de aula. Essas reflexões nos levaram a pensar a elaboração de um protótipo didático para as aulas de literatura. Para tanto, foram necessários estudos de novas teorias e várias tentativas para que o app se transformasse em um instrumento de ensino e de aprendizagem da leitura. 
Segundo Rojo (2013) os novos meios de aprendizagem virtual podem ser utilizados pela escola para: (a) ampliar esferas de atividades; (b) diversificar os letramentos literários; (c) propiciar novas formas de aprendizagem. A autora destaca que desenvolver o trabalho de recepção de obras literárias bem como o de produção, seja por qualquer tecnologia, deve acompanhar uma postura crítica e reflexiva do professor e do aluno.

O aplicativo educacional surge, assim, como uma dessas opções para que o professor possa elaborar o seu material didático. O desenvolvedor do app aqui produzido é a Fábrica de Aplicativos ${ }^{5}$, ou seja, uma plataforma virtual com infinitas possibilidades e gratuita. Através de um editor que arrasta e solta, o professor/produtor do app vai adicionando recursos que o ajudam a organizar o conteúdo, aplicar design e aproveitar dezenas de templates e modelos já prontos. Mesmo sem saber programar e sem conhecimento técnico, o professor/produtor consegue desenvolver os conteúdos do aplicativo, conforme os menus do software, e expandir a sua criatividade. Além disso, pode contar com um suporte especializado que vai oferecendolhe instruções sobre o emprego de cada recurso disponível na plataforma.

Após a conclusão do app, o professor/produtor pode publicar o seu trabalho gratuitamente na web em html ou contratar um plano na Google Play para Android e App Store para iPhone. Os apps feitos pela Fábrica de Aplicativos em contas gratuitas são para smartphones e podem ser acessados também pelos navegadores Chrome, Safari entre outros. Se o professor/produtor do app optar por uma conta paga, o aplicativo poderá ser publicado e baixado nas lojas do Google, a Play Store e Apple, App Store e sua visualização difundida.

Nota-se que o aplicativo educacional é um suporte de fácil acesso pelo aluno/leitor e contribui para o desenvolvimento da multimodalidade da linguagem. Além disso, trata-se de uma forma instigante de propiciar um ensino interativo ao estudante, constituindo-o como sujeito de seu dizer e fazer, além de outorgar ao professor a função de produtor e mediador no processo de ensino e aprendizagem. O suporte consiste em uma inovação no processo de ensino-aprendizagem da leitura nas escolas, pois reúne softwares para Android que podem ser utilizados e modificados livremente, ou seja, são softwares educacionais livres para celulares, tablets, notebooks, etc. É um Recurso Educacional Aberto ${ }^{6}$ (REA) usado para designar um material educativo licenciado de forma pública, permitindo que qualquer pessoa interessada use ou adapte o conteúdo da forma como preferir.

\footnotetext{
${ }^{5}$ Disponível em: https://fabricadeaplicativos.com.br/termos. Acesso em: 17 jul. 2018.

${ }^{6}$ Ver mais sobre o REA em: http://www.rea.net.br/site/. Acesso em: 28 jan. 2018.
} 
O protótipo que elaboramos trata-se de um aplicativo móvel que nos desafiou, mas também nos proporcionou uma série de aprendizagens. Oferece sugestões de atividades que podem ser desenvolvidas com alunos do $9^{\circ}$ ano, e tem como título: "Uma proposta de multiletramento literário". Procuramos definir o tema de abertura utilizando a figura de uma lupa e um livro na tentativa de manter relação com o suspense, mistério, investigação e revelação que se sucedem no decorrer da obra "A droga da obediência". E, como ícone de acesso ao aplicativo, inserimos uma silhueta humana também com uma lupa, corroborando a ideia dos enigmas a serem desvendados durante a leitura.

Ao clicar no título, o usuário depara-se com a tela inicial composta de sete abas para o usuário acessar e trabalhar composta de: (a) A DROGA DA OBEDIÊNCIA (o protótipo didático) (b) uma BIBLIOTECA com acervo para uso do professor e do aluno; (c) ÁUDIOS e VÍDEOS contendo também material para o professor e para o aluno; (d) ÁLBUM com ilustrações da obra; (e) INFORMAÇÕES sobre os direitos autorais do aplicativo; (f) MURAL de participação do leitor; ( $\mathrm{g}$ ) endereço de CONTATO das autoras.

Fig. 3 -Tela inicial do protótipo

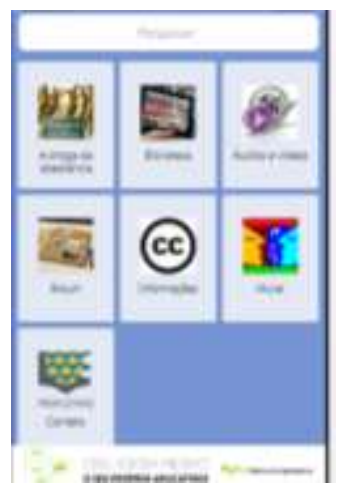

Fonte: As autoras.

Ao clicar na primeira aba, intitulada A DROGA DA OBEDIÊNCIA, o usuário passará por subabas com a apresentação do trabalho, considerações sobre as teorias que embasam o trabalho, apresentação da obra a ser lida e atividades de leitura com base na sequência expandida de Cosson (2014): motivação, introdução, leitura, interpretação, contextualização e expansão, conforme atesta o quadro 2 abaixo:

Quadro 2- SubAbas do protótipo didático "A droga da Obediência”

\begin{tabular}{|l|l|l|}
\hline \multicolumn{1}{|c|}{ TITULO } & \multicolumn{1}{|c|}{ OBJETIVO } & ATIVIDADES/HIPERLINKS \\
\hline $\begin{array}{l}\text { CONSIDERAÇÕES } \\
\text { INICIAIS }\end{array}$ & $\begin{array}{l}\text { Apresentar o aplicativo e a } \\
\text { finalidade do trabalho. }\end{array}$ & https://app.vc/adrogadaobediencia \\
\hline
\end{tabular}




\begin{tabular}{|c|c|c|}
\hline & $\begin{array}{l}\text { Justificar a produção do } a p p \text {, } \\
\begin{array}{lr}\text { Esclarecer os objetivos e } \\
\text { princípios } & \text { teóricos } \\
\text { norteadores do protótipo } \\
\text { didático. }\end{array} \\
\end{array}$ & \\
\hline $\begin{array}{ll}\text { SEQUENNCIA } & \text { DIDÁTICA } \\
\text { EXPANDIDA } & \end{array}$ & $\begin{array}{l}\text { Apresentar ao professor o } \\
\text { método de leitura de Cosson } \\
\text { (2014) utilizado pelo } \\
\text { protótipo. }\end{array}$ & https://app.vc/adrogadaobediencia \\
\hline A OBRA & $\begin{array}{lll}\text { Apresentar ao } & \text { professor a } \\
\text { obra "A } & \text { droga da } \\
\text { obediência" } & \text { de } & \text { Pedro } \\
\text { Bandeira. } & & \\
\end{array}$ & https://app.vc/adrogadaobediencia \\
\hline $\begin{array}{l}\text { MOTIVANDO } \\
\text { LEITURA }\end{array}$ & $\begin{array}{l}\text { Possibilitar ao aluno } \\
\text { desvendar mistérios e } \\
\text { resolver problemas por meio } \\
\text { de atividades lúdicas. } \\
\text { Desenvolver a interatividade } \\
\text { do aluno com a leitura e } \\
\text { colegas por meio de recurso } \\
\text { midiático. }\end{array}$ & $\begin{array}{l}\text { Atividade } 1 \text { - Brincadeira de detetive (sala } \\
\text { de aula): As cadeiras devem estar dispostas } \\
\text { em círculo com todos os alunos sentados. } \\
\text { Sorteiam-se papéis aos participantes. Em um } \\
\text { dos papéis estará escrito a palavra } \\
\text { DETETIVE, em outro, a palavra } \\
\text { ASSASSINO e nos demais, a palavra } \\
\text { VÍTIMA. Cada aluno deve ler e manter } \\
\text { segredo sobre a sua função. O assassino tem } \\
\text { a tarefa de "matar" as vítimas com uma } \\
\text { piscada, mas deve tomar cuidado para não ser } \\
\text { descoberto pelo detetive. Se isso acontecer, o } \\
\text { detetive diz: "você está preso em nome da } \\
\text { lei!". Já o papel da vítima é prestar atenção } \\
\text { em todos os olhares, ser muito discreta e } \\
\text { esperar que seja "morta", neste momento ela } \\
\text { diz "morri" e sai do círculo. A brincadeira } \\
\text { acaba quando o assassino consegue eliminar } \\
\text { todas as vítimas, ou no momento em que o } \\
\text { detetive descobre quem é o assassino. O } \\
\text { sorteio pode ser realizado várias vezes para } \\
\text { que se reinicie a brincadeira. } \\
\text { Atividade } 2 \text { - Desvendando enigmas por } \\
\text { meio de Vídeo (sala de aula) ou internet: } \\
\text { https://youtu.be/sVmqksvxen47 } \\
\text { Vídeo-Desvendando } \\
\text { https://youtu.be/sVmqksvxen } 4^{8}\end{array}$ \\
\hline $\begin{array}{l}\text { INTRODUZINDO } \\
\text { LEITURA }\end{array}$ & 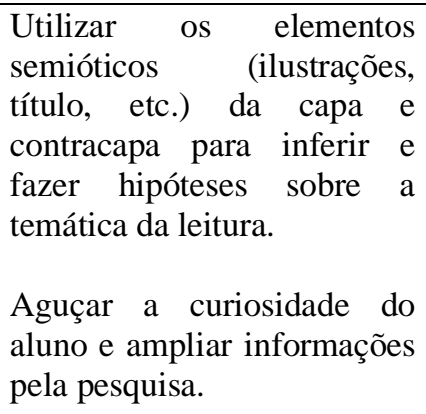 & $\begin{array}{l}\text { Links de pesquisa: } \\
\text { https://youtu.be/aJG8xSJhSHs (7: } 33 \mathrm{~min})^{9} \\
\text { https://livrada.files.wordpress.com/2015/11/ } \\
\text { 121241071_1gg.jpg?w=370\&h } \mathbf{=}^{\mathbf{1 0}} \text { (capa do } \\
\text { livro) }\end{array}$ \\
\hline
\end{tabular}

\footnotetext{
${ }^{7}$ Acesso em: 17 jul. 2018.

${ }^{8}$ Acesso em: 17 jul. 2018.

${ }^{9}$ Acesso em: 17 jul. 2018.

${ }^{10}$ Acesso em: 15 jul. 2018.
} 


\begin{tabular}{|c|c|c|}
\hline & $\begin{array}{l}\text { Desenvolver habilidades de } \\
\text { leitura e navegação online. }\end{array}$ & $\begin{array}{l}\text { https://capasdelivrosbrasil.blogspot.com/201 } \\
\text { 6/11/pedro-bandeira-a-droga-da- } \\
\text { obediencia.html }{ }^{11} \text { (obras de Pedro Bandeira) } \\
\text { https://docs.google.com/document/d/1LxMJ } \\
\text { B-gkrxE7HZ90T- } \\
\text { fWi_PVCrdpahQ1Qdh2zrF15BI/edit?usp=s } \\
\text { haring }{ }^{12} \text { (contracapa) } \\
\text { Vídeo: https://youtu.be/NCbJHMvWLt813 } \\
\text { Link das atividades pelo Google Formulário: } \\
\text { https://goo.gl/forms/H5fNPWDJaX1AIe1p1 }\end{array}$ \\
\hline $\begin{array}{l}\text { LEITURA - CAPÍTULO I - } \\
\text { OS KARAS }\end{array}$ & $\begin{array}{l}\text { Conhecer as personagens } \\
\text { centrais da narrativa. } \\
\text { Desvendar espaço/tempo da } \\
\text { narrativa. } \\
\text { Desenvolver habilidades de } \\
\text { navegação e leitura online. }\end{array}$ & $\begin{array}{l}\text { 1. Links de acesso à obra na íntegra: } \\
\text { http://livros-online- } \\
\text { now.blogspot.com.br/2014/02/a-droga- } \\
\text { da-obediencia.html } 15 \\
\text { 2. http://www.excelenciaemtudo.com.br/a } \\
\text { rquivos/ef/a_droga_da_obediencia.pdf } \\
\text { 16 } \\
\text { 3. Atividade oral: } \\
\text { a) O primeiro capítulo da obra apresenta } \\
\text { as personagens que irão protagonizar a } \\
\text { história. Quais são elas? } \\
\text { b) Há algum traço descrito, logo no } \\
\text { primeiro capítulo, que comprova a } \\
\text { liderança de Miguel no grupo Karas? } \\
\text { c) O que Miguel fazia na biblioteca da } \\
\text { escola quando iniciou a história? } \\
\text { d) Pelo nome e atividades preferidas, } \\
\text { como deveria ser Crânio? Que relação } \\
\text { haveria entre essa personagem e as } \\
\text { características de uma obra de enigma } \\
\text { policial? } \\
\text { e) Pela descrição de Magri, quais seriam } \\
\text { os seus talentos? Qual poderia ser a } \\
\text { utilidade dos alentos de Magri para o } \\
\text { desenvolvimento da narrativa? } \\
\text { E) Qm que atividade se destacava Calu na } \\
\text { escola? O que isso pode estar } \\
\text { relacionado à história a ser lida? } \\
\text { Descreva-o. Que importância poderia } \\
\text { ter essa personagem para a história aser } \\
\text { lida? } \\
\text { adotado pelo grupo Karas. Como ele e } \\
\text { o grupo reagiram a isso? E como ele } \\
\text { teria descoberto o grupo? }\end{array}$ \\
\hline
\end{tabular}

\footnotetext{
${ }^{11}$ Acesso em: 15 jul. 1028

${ }^{12}$ Acesso em: 15 jul. 2018.

${ }^{13}$ Acesso em: 16 jul. 2018.

${ }^{14}$ Acesso em: 16 jul. 2018.

${ }^{15}$ Acesso em: 16 jul. 2018.

${ }^{16}$ Acesso em: 16 jul. 2018.
} 


\begin{tabular}{|c|c|c|}
\hline INTERVALO & $\begin{array}{l}\text { Identificar elementos da obra } \\
\text { A Droga da Obediência por } \\
\text { meio de atividades lúdicas. } \\
\text { Conhecer obras/ personagens } \\
\text { e características de narrativas } \\
\text { de enigmas policial. } \\
\text { Desenvolver habilidades de } \\
\text { leitura e navegação online. }\end{array}$ & $\begin{array}{l}\text { Quizzes jogos): } \\
\text { https://rachacuca.com.br/quiz/66581/a- } \\
\text { droga-da-obediencia-i/17 } \\
\text { http://www.quizzes.com.br/pt/quiz/4557750 } \\
\text { 51/narrativas-de-enigmas-policiais }{ }^{18} \\
\text { https://rachacuca.com.br/quiz/11411/os- } \\
\text { karas-de-pedro-bandeira/ }{ }^{19}\end{array}$ \\
\hline $\begin{array}{l}\text { CONTEXTUALIZANDO A } \\
\text { OBRA }\end{array}$ & $\begin{array}{l}\text { Desenvolver hábito de } \\
\text { pesquisa pelo acesso de } \\
\text { hiperlinks. } \\
\text { Ganhar habilidades técnicas } \\
\text { e tecnológicas para usar o } \\
\text { aplicativo do Google: } \\
\text { Google Documentos. }\end{array}$ & $\begin{array}{l}\text { Pesquisa sobre crianças, adolescentes e } \\
\text { jovens desaparecidos, pela internet: } \\
\text { https://noticias.r7.com/cidades/com-40-mil- } \\
\text { criancas-desaparecidas-por-ano-brasil- } \\
\text { abandona-ferramenta-de-localizacao- } \\
25052015^{20} \\
\text { https://batistacarioca.com.br/criancas- } \\
\text { desaparecidas/21 } \\
\text { http://fefcriancasdesaparecidasajudelocaliza. } \\
\text { blogspot.com/2011/09/recomendacoes-para- } \\
\text { evitar-o-sequestro.html2 } \\
\text { Vídeo: https://youtu.be/F7ARFCrMb1w }{ }^{23} \\
\text { Produção de texto do aluno por meio do } \\
\text { Google Docs. }\end{array}$ \\
\hline $\begin{array}{l}\text { ANÁLISE DOS DEMAIS } \\
\text { CAPÍTULOS DA OBRA }\end{array}$ & $\begin{array}{l}\text { Identificar as demais } \\
\text { personagens, o tema e o } \\
\text { estilo do autor. } \\
\text { Manter relações entre as } \\
\text { vozes do texto, identificando } \\
\text { as ideologias do discurso. } \\
\text { Desenvolver habilidades de } \\
\text { acesso ao Google Drive, } \\
\text { aprendendo a lidar com o } \\
\text { Google Forms. }\end{array}$ & $\begin{array}{l}\text { Professor, as questões a seguir devem ser } \\
\text { discutidas oralmente com os alunos, na } \\
\text { classe, e respondidas por eles, depois, de } \\
\text { forma digital pelo link: } \\
\text { https://goo.gl/forms/H6KG5COFa74OfeRy1 }\end{array}$ \\
\hline $\begin{array}{l}\text { INTERVALO } \\
\text { EXPANSÃO DA LEITURA }\end{array}$ & $\begin{array}{l}\text { Associar o conteúdo temático } \\
\text { do filme com o da obra, } \\
\text { analisando as características } \\
\text { que as aproximam. } \\
\text { Desenvolver a interação oral } \\
\text { com os colegas, ganhando } \\
\text { mais segurança na fala }\end{array}$ & $\begin{array}{l}\text { Filme - Divergente } \\
\text { https://www.telecineplay.com.br/filme/Diver } \\
\text { gente_3595?utm_source=adoro- } \\
\text { cinema\&utm_medium=filmes\&utm_content } \\
=\text { Divergente\&utm_campaign=adoro- } \\
\text { cinema }{ }^{24}\end{array}$ \\
\hline
\end{tabular}

${ }^{17}$ Acesso em: 15 jul. 2018.

${ }^{18}$ Acesso em: 15 jul. 2018.

${ }^{19}$ Acesso em: 15 jul. 2018.

${ }^{20}$ Acesso em: 16 jul. 2018.

${ }^{21}$ Acesso em: 16 jul. 2018.

${ }^{22}$ Acesso em: 16 jul. 2018.

${ }^{23}$ Acesso em: 16 jul. 2018.

${ }^{24}$ Acesso em: 16 jul. 2018. 


\begin{tabular}{|c|c|c|}
\hline & $\begin{array}{l}\text { organizada e uso de } \\
\text { argumentos. } \\
\text { Desenvolver habilidades de } \\
\text { leitura e navegação online. }\end{array}$ & $\begin{array}{l}\text { Trailer: https://youtu.be/B_fty0k6SNI }{ }^{25} \\
\text { Algumas sugestões para o cotejo oral entre a } \\
\text { obra e o filme: } \\
\text { 1. Que relação haveria entre a sociedade } \\
\text { da narrativa de Pedro Bandeira e a } \\
\text { apresentada pelo filme? O que elas têm } \\
\text { em comum? } \\
\text { 2. O que se passa no livro e no filme teria } \\
\text { alguma relação com a sociedade em que } \\
\text { vivemos hoje? Como se percebe isso } \\
\text { 3. O que teriam em comum as personagens } \\
\text { principais Miguel e Tris? } \\
\text { Que personagem do filme da série } \\
\text { Divergente você seria? Por quê? } \\
\text { Observe que Tris, logo no início do } \\
\text { filme, teve que fazer escolhas. Miguel } \\
\text { também faz ao optar pelo lado dos } \\
\text { inocentes e das vítimas dos sequestros. } \\
\text { E você, que escolhas já fez e que foram } \\
\text { significativas em sua vida? }\end{array}$ \\
\hline $\begin{array}{l}\text { CONTEXTUALIZAÇÃO E } \\
\text { EXPANSÃO DA LEITURA }\end{array}$ & $\begin{array}{l}\text { Manter relação entre obras e } \\
\text { textos, analisando o aspecto } \\
\text { formal, o estilo e o conteúdo } \\
\text { temático. } \\
\text { Identificar as ideias } \\
\text { explícitas e implícitas da } \\
\text { leitura por meio da relação } \\
\text { entre os textos. } \\
\text { Desenvolver habilidades de } \\
\text { leitura e navegação. } \\
\text { Manter relações do texto com } \\
\text { as situações do cotidianas. }\end{array}$ & 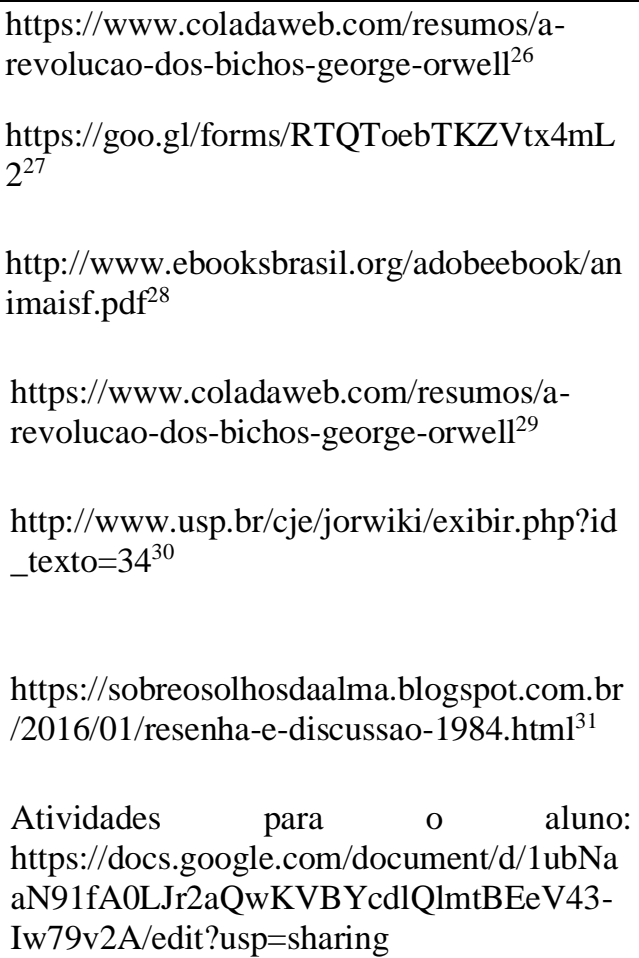 \\
\hline INTERVALO & $\begin{array}{l}\text { Rever elementos da obra } \\
\text { lida; }\end{array}$ & $\begin{array}{l}\text { Cruzadinha: } \\
\text { https://docs.google.com/document/d/1THgu }\end{array}$ \\
\hline
\end{tabular}

\footnotetext{
${ }^{25}$ Acesso em: 16 jul. 2018.

${ }^{26}$ Acesso em: 14 jul. 2018.

${ }^{27}$ Acesso em: 14 jul. 2018.

${ }^{28}$ Acesso em: 14 jul. 2018.

${ }^{29}$ Acesso em: 14 jul. 2018.

${ }^{30}$ Acesso em: 14 jul. 2018.

${ }^{31}$ Acesso em: 14 jul. 2018.
} 


\begin{tabular}{|c|c|c|}
\hline & $\begin{array}{l}\text { Avaliar a interação do aluno- } \\
\text { texto. } \\
\text { Adquirir habilidades pela } \\
\text { navegação online. }\end{array}$ & $\begin{array}{l}\text { z-ZNiD6bvG06xYB3o7maLlGi_- } \\
\text { EH995ld4mCNjA/edit?usp=sharing } \\
\text { Caça-palavras: } \\
\text { https://docs.google.com/document/d/1LfwE } \\
\text { oPp_deYXABRlgk7xN1QEKydU4oVpZ5k } \\
\text { xRkyLM2g/edit?usp=sharing } \\
\text { https://www.imagem.eti.br/caca- } \\
\text { palavras/caca-palavras-a-revolucao-dos- } \\
\text { bichos-est.php }{ }^{32} \\
\text { Carta enigmática: } \\
\text { https://docs.google.com/document/d/1ipJtit- } \\
\text { FtMWYqQpclYKOLuIvmwcOL0TXDyne } 2 \mathrm{j} \\
\text { dnTSQ/edit?usp=sharing }\end{array}$ \\
\hline $\begin{array}{l}\text { INTERPRETAÇÃO } \quad \text { DA } \\
\text { LEITURA }\end{array}$ & $\begin{array}{l}\text { Desenvolver a interação } \\
\text { aluno-aluno pela discussão } \\
\text { coletiva das ideias centrais da } \\
\text { leitura. } \\
\text { Responder ao processo de } \\
\text { leitura por meio da oralidade, } \\
\text { escrita ou recurso digital. }\end{array}$ & $\begin{array}{l}\text { Atividades para } \quad \text { o } \\
\text { https://goo.gl/forms/86mmccDJ6ukeWehk1 }\end{array}$ \\
\hline
\end{tabular}

Fonte: as autoras

Ao ativar busca na aba BIBLIOTECA, o usuário do aplicativo encontrará o texto da obra "A droga da obediência" na íntegra; as diferentes obras do autor Pedro Bandeira e sua biografia; informações sobre o romance noir e o romance policial (FAJARDO, 2014); concepções de leitura de Cosson; e artigos e reportagens sobre a obra. Além disso, o aplicativo oferece na aba ÁUDIOS e VÍDEOS: um filme realizado por alunos sobre a obra; um áudio da obra; uma entrevista com Pedro Bandeira; youtubers comentando as obras 1984 e Revolução dos Bichos de George Orwell; vídeos sobre o romance noir; vídeos sobre Candido e a literatura; vídeos sobre a vida e obras de Agatha Christie; e filmes com a personagem detetivesca Sherlock Holmes de Arthur Conan Doyle.

É importante ressaltarmos o caráter multimodal do protótipo, bem como a necessidade do envolvimento do professor durante as atividades cotidianas de sala de aula, pois há atividades, especialmente quanto à sequência expandida, que necessitam da mediação. Deste modo, sugerimos ao professor a aprendizagem por meio dos recursos digitais móveis, visto que muitas atividades podem ser realizadas em outros espaços que não sejam os da escola. Nessa modalidade, o aluno acessa o app, realiza as atividades digitais, que, após concluídas, são enviadas online ao professor pelos recursos do Google Drive: o Google Formulário e/ou Google

${ }^{32}$ Acesso em: 14 jul. 2018. 
Documento. Assim, ao exercitar o uso deste software junto ao aluno do Ensino Fundamental II, o professor estará cooperando para que o horizonte de pesquisa e de leitura do estudante se amplie, de forma que este ganhe mais autonomia e aguce a sua curiosidade para novas possibilidades de interação pela internet para uso do conhecimento literário.

Importa, dessa forma, ao professor, por meio da diversidade de recursos que as tecnologias digitais oferecem, valorizar diferentes produções culturais, impressas ou digitais, populares ou clássicas, ciente de que trabalhar a leitura na escola é possibilitar ao aluno/leitor refletir e compreender a vida e se apoderar de condições linguísticas, emocionais, estéticas, éticas, etc., para viver de forma mais digna, humana e solidária. Com isso, espera-se que o estudante seja um coautor da obra/texto, discutindo, mantendo relações, aceitando, negando, perguntando, contextualizando, compreendendo, interpretando e reescrevendo o que leu, assumindo, enfim, diferentes atitudes responsivas, mantendo uma relação com uma leitura que tenha sentido para a sua vida, confirmando assim as teorias enunciativas da linguagem aqui ressaltadas.

\section{Conclusão}

Orientados por estudos provenientes do curso Profletras/UEM sobre a concepção enunciativa da linguagem bakhtiniana, que enfoca a linguagem como uma prática social real e concreta e que leva em conta uma situação real, um destinatário, uma finalidade, os sujeitos da interlocução (leitor/autor), a interatividade, as relações intertextuais e as dialógicas dos discursos, os cronotopos, um conteúdo temático, um certo estilo individual de produzir, uma estrutura formal, uma superestrutura, produzimos um protótipo didático endereçado ao professor de português.

Com o propósito de suscitar no estudante do nono ano do ensino fundamental o entusiasmo e o empenho pela leitura, de modo que este venha desenvolver o multiletramento literário, elaboramos este material disponibilizando-o em um aplicativo móvel (app). Para isso, optamos pela obra de Pedro Bandeira “A Droga da Obediência, pretendendo proporcionar aos alunos/leitores conhecer o gênero literário de enigma policial para discutir, refletir, compreender, interpretar, contextualizar, complementar, aceitar, negar e expandir horizontes pela leitura, tanto pelo processo convencional quanto por meio digital.

Com a linguagem semiótica do aplicativo, contamos que o aluno/usuário se sinta estimulado a interagir com a leitura de mistérios/enigmas proposta, não apenas pela obra Bandeira, mas, também pelos filmes, áudios, tira, jogos e outras modalidades da linguagem 
inseridas neste trabalho. Para tanto, seguimos as etapas sugeridas pela sequência didática de leitura de Cosson (2014): motivação, introdução, leitura, interpretação, contextualização e expansão. As atividades exploradas pelo protótipo visam aguçar de forma cognitiva e lúdica o interesse do estudante pela leitura e pela criação artística - literária, levando em conta a sua formação pessoal, cultural e social, preparando-o para a vida.

Esperamos também que o professor/usuário deste aplicativo, ao mediar as atividades sugeridas neste protótipo, possibilite ao seu aluno uma nova forma de ler e de construir a aprendizagem, apresentando-lhe condições para desenvolver novas habilidades pela incorporação das tecnologias digitais (escrita e leitura digitais, navegação online, uso de hipertextos, acesso a hiperlinks) às convencionais (oralidade, impresso e leitura/escrita convencional), de modo que o estudante possa se inserir nas múltiplas esferas de circulação, atuando de forma autônoma e reflexiva e tornando-se coautor da leitura.

Além disso, ao reelaborar e aplicativo, considerando a realidade de sua sala de aula, o professor/usuário estará deixando de ser um mero consumidor de material de ensino, adaptando as atividades: complementando-as, ampliando-as, refutando algumas e substituindo outras, contribuindo para uma nova forma de lidar com a literatura na escola, confirmando o seu papel de autor (a) e de orientador/colaborador/motivador e destacando o aluno como um personagem ativo e central do processo de ensino e aprendizagem.

\section{Referências}

BAKHTIN, M. M. (Volochínov). Marxismo e filosofia da linguagem. Trad. Michel Laud e Yara F. Vieira, São Paulo: Hucitec, 1992.

BAKHTIN, M. Os gêneros do discurso. In: BAKHTIN, M. Estética da criação verbal. São Paulo: Martins Fontes, 2003 [1979].

BANDEIRA, Pedro. A droga da obediência. 5. ed. São Paulo: Editora Moderna, 2014.

BRASIL. Base nacional comum curricular. Aprovada em dezembro de 2017. Disponível em: http://basenacionalcomum.mec.gov.br/. Acesso em: 01 de jun. 2018.

CANDIDO, Antônio. O direito à literatura. In: CÂNDIDO, Antônio. Vários Escritos. São Paulo: Duas Cidades, 1995, p.169.

CANDIDO, Antônio. Literatura e sociedade: estudos de teoria e história literária. 8. ed. São Paulo: T.A. Queiroz, 2000.

CANDIDO, Antônio. A literatura e a formação do homem. In: CÂNDIDO, Antônio. Textos de Intervenção. São Paulo: Editora 34/ Duas Cidades, 2002, p. 77-92.

COMPAGNON, Antoine. Literatura pra quê? Tradução de Laura Taddei Brandini. Belo Horizonte: Editora UFMG, 2009. 
COSSON, Rildo. Letramento literário: teoria e prática. 2 ed. São Paulo: Editora Contexto, 2014. Texto em PDF. Disponível em: https://moodlep.uem.br/course/view.php?id=1208. Acesso em: 19 nov. 2017.

DA SILVA \& SOUZA. N. T/ E. M. F. O uso do protótipo didático como estratégia para o ensino de língua portuguesa. Pensares em Revista, São Gonçalo-RJ, n. 7, pág.127-143, jul/dez. 2015. ISSN 2517-2215.

FAJARDO, Andressa. Luís Dill e a narrativa para jovens: o gênero policial. Dissertação de mestrado. Maringá: UEM, 2014, 178 p. Disponível em: http://www.ple.uem.br/defesas/pdf/afajardo.PDF. Acesso em: 20 nov. 2017.

GARCIA - CANCLINI, Nestor. Culturas Híbridas: Estratégias para entrar e sair da modernidade. São Paulo: Edusp, 2008[1989].

MARSARO-PAVAN, Fabiana. Dos livros didáticos aos protótipos de ensino: em direção a um web-currículo. Revista Triângulo, Uberaba, MG v.10 n.1, p. 96-111 Jan.-Jun./2017 ISSN 2175-1609.

ROJO, Roxane Helena Rodrigues. Multiletramentos literários. São Paulo: Parábola Editorial, 2012.

ROJO, Roxane Helena Rodrigues; ALMEIDA, Eduardo de Moura (Orgs.). Multiletramentos na escola. São Paulo: Parábola Editorial, 2012. 264 p.

ROJO, Roxane Helena Rodrigues. H. Entre plataformas, odas e protótipos: Novos multiletramentos em tempo deweb2. The ESPecialist: Descrição, Ensino e Aprendizagem, Vol. 38 No. 11 jan-jul $2017 . \quad$ Disponível https://www.researchgate.net/publication/318739106_Entre_Plataformas_ODAs_e_Prototipos _Novos_multiletramentos_em_tempos_de_WEB2. Acesso em: 16 nov. 2017. 